\title{
O papel do conhecimento de eventos no processamento de sentenças isoladas
}

\author{
The role of event knowledge in the processing of single sentences
}

Mahayana Cristina Godoy¹, Cláudia Brandão Vieira², Guilherme Luiz Andrade ${ }^{3}$, Neemias de Souza Filho4, Marcus Alexandre Nunes ${ }^{5}$

Doutora em Linguística pela Unicamp. Professora Adjunta na Universidade Federal do Rio Grande do Norte.

E-mail: mgodoy@cchla.ufrn.br

ma de Pós-graduacão em Estudos Linguisticos da Universidade Federal de Minas Gerais.

E-mail: claubrandaov@gmail.com

Graduando em Letras/Francês na Universidade Federal do Rio Grande do Norte.

E-mail: guillass@gmail.co Federal do Rio Grande do Norte.

E-mail: neemiassfilho@gmail.com University. Professor Adjunto na Universidade Federal do Rio Grande do Norte. @gmail.con
RESUMO: 0 presente artigo tem como objetivo investigar o papel do conhecimento de eventos no processamento linguístico. Evidências empíricas obtidas através de estudos em psicolinguística argumentam que o conhecimento de eventos faz parte de uma coleção de pistas pragmáticas que impactam o processo de compreensão da linguagem. No entanto, o experimento de leitura autocadenciada que conduzimos para investigar a questão não registra qualquer efeito nesse sentido, indicando que o conhecimento de evento, se acessado, não influenciou o processamento de palavras específicas em sentenças isoladas e de contexto preditivo. Considerando que tal resultado contraria uma série de achados prévios, argumentamos que (a) a natureza do efeito documentado por estudos anteriores precisa ser melhor explicada e explorada; (b) o modo de apresentação dos itens experimentais pode levar à adoção de estratégias distintas de processamento, o que explicaria a divergência de resultados; (c) algumas técnicas como leitura autocadenciada podem não ser sensíveis para captar o mesmo efeito registrado por meio de outros paradigmas. Embora a segunda explicação pareça mais razoável para dar conta de nossos dados, apenas futuras pesquisas poderão decidir pela sua validade.

Palavras-chave: Conhecimento de eventos; Compreensão linguística; Processamento de sentenças; Leitura autocadenciada.

ABSTRACT: In this paper, we investigate the role of event knowledge in language processing. Empirical research in psycholinguistics argue that event knowledge is part of a set of pragmatic cues that can impact language comprehension. However, a self-paced reading experiment presented here has found no evidence of this effect, indicating that event knowledge, if accessed by readers, did not have any influence in the processing of single sentences that create a highly predictive context. Because this result contradicts previous findings, we argue that (a) the nature of the effects reported by previous experiments needs to be examined; (b) the way experimental items are presented may lead to the adoption of different processing strategies, which could explain the contradiction captured by our experiment; (c) paradigms such as self-paced reading may not be adequate to register the same effects captured by other techniques. Although the second hypothesis may be more suitable to account for our data, we state that it could only be validated by future research on this topic.

Keywords: Event knowledge; Language comprehension; Sentence processing; Self-paced reading. 


\section{Introdução}

percepção de que o conhecimento pragmático é um dos fatores centrais - para o processamento linguístico não é nova e sustenta-se por inúmeras evidências empíricas obtidas nas últimas décadas. Esse conhecimento, na literatura, é caracterizado como fatores extrassentenciais, que afetam o processo incremental de compreensão linguística (VAN BERKUM, 2009), e pode cobrir uma gama de informações tão variadas quanto a voz do interlocutor (VAN BERKUM et al., 2008), a sua intenção comunicativa (BASNÁKOVÁ et al., 2015), pistas não-verbais no contexto imediato (KAMIDE et al., 2003), a informatividade do contexto (NIEUWLAND, DITMAN e KUPERBERG, 2010) ou a representação discursiva (FEDERMEIER, 1999; VAN BERKUM et al., 2005). Em comum a todos esses casos, há a premissa de que as inferências feitas pelo ouvinte/leitor, a partir de seu conhecimento de mundo, impactariam o modo como informações de ordem linguística são processadas.

Resultados de experimentos que fizeram uso de técnicas tão variadas quanto a leitura autocadenciada e eletroencefalografia indicam que esse conhecimento de mundo é capaz de impactar o processamento semântico (HAGOORT et al., 2004), de sobrepor-se a traços lexicais (NIEUWLAND e VAN BERKUM, 2006) ou de influenciar a facilidade com que se processam determinadas estruturas sintáticas (TANENHAUS, 1995). Ademais, na última década, uma série de estudos tem encontrado evidências robustas de que informações pragmáticas são capazes de antecipar traços formais do input linguístico subsequente em níveis tão variados quanto o fonológico (DELONG et al., 2005) e o morfológico (WICHA et al., 2004). Em outras palavras, esses resultados indicam que, antes mesmo de serem lidas/ ouvidas, informações linguísticas estruturais como gênero gramatical podem ser antecipadas com base em restrições impostas por informações pragmáticas ${ }^{1}$. Esses indícios apontam que informações como conhecimento de mundo podem atuar no processamento linguístico desde o primeiro momento, e tornam datadas propostas que advogam que seu efeito se faria sentir apenas em um momento posterior.

A tentativa de explicar esses dados resultou na criação de modelos de processamento que explicam o processador linguístico como um mecanismo que se guia, em maior ou menor grau, por processos de orientação top-down, isto é, pelo princípio de que informações referentes à representação discursiva, intenções do falante/ouvinte ou inferências necessárias à construção do sentido influenciariam o processamento da estrutura linguística. Nessa esteira, estabelecem-se modelos que assumem um processamento linguístico flexível e adaptável ao contexto de interação e capaz de gerar expectativas sobre o input linguístico subsequente com base em informações das mais diversas ordens (KUPERBERG, 2016; KUPERBERG e JAEGER, 2015).

Um dos desafios desses modelos é formalizar a maneira pela qual pistas pragmáticas agem durante o processamento linguístico. Embora a maioria dos modelos - mesmo os de natureza bottom-up - não neguem que o conhecimento pragmático influencia o processamento linguístico em algum momento, cabe aos modelos que lhe dão destaque a tarefa de especificar questões como (a) de que se trata esse tipo de conhecimento; (b) como ele interage com o estímulo linguístico disponível, complementando-o ou sobrepondo-se a ele; (c) que pistas são usadas para construirmos inferências pragmáticas capazes de guiar o processamento da linguagem.

${ }^{1}$ Não tentaremos, nesse artigo, fazer uma distinção entre modelos integrativos e modelos preditivos para explicar diferenças de processamento (cf. GODOY et al., 2016) para uma revisão sobre o assunto). No entanto, assumimos aqui que os efeitos de facilitação ou dificuldade de processamento são melhor explicados por modelos em expectativas, seguindo trabalhos da área (DELONG et al., 2005). 
Buscando contribuir para essas questões, o presente trabalho propõe uma investigação empírica através de um experimento de leitura autocadenciada desenhado para avaliar como o conhecimento sobre eventos um tipo de conhecimento pragmático - agiria durante o processamento linguístico. Uma vez que os resultados de um trabalho em português sobre a questão (VIEIRA, 2015) apresentaram dados incompatíveis com os observados para o inglês (BICKNELL et al., 2010), nosso objetivo específico foi averiguar se o tempo de leitura do argumento interno de alguns verbos depende de seu nível de previsibilidade em uma sentença que denota um evento específico. Dito de outro modo, investigamos se a probabilidade com que determinada palavra está associada ao evento denotado pela sentença influencia o seu tempo de leitura.

Nossos resultados não registraram tal efeito, o que abre uma série de questões não sobre a existência da influência do conhecimento de eventos no processamento linguístico, mas sobre como esse conhecimento atua no processo de compreensão da linguagem. Conforme debateremos na seção de discussão, nossos dados podem ser explicados a partir de hipóteses acerca (i) da natureza dos efeitos reportados por estudos anteriores, (ii) das diferentes estratégias de processamento ativadas por diferentes contextos experimentais, (iii) dos limites de técnicas experimentais comportamentais.

Antes de tratar dessas possíveis explicações, começaremos nosso trabalho com uma breve revisão sobre a influência do conhecimento sobre eventos no processamento linguístico e o levantamento de hipóteses que guiaram nosso estudo experimental.

\section{Conhecimento de evento e processamento linguístico}

Grande parte do que sabemos sobre o mundo real pode ser caracterizado como conhecimentos sobre eventos e estados. Resumidamente, pode-se afirmar que o conhecimento de eventos envolve um conjunto de informações a respeito da maneira como o mundo real se organiza. Essas informações provocam expectativas acerca de entidades propícias a ocuparem determinados papéis e de lugares propícios a abrigarem determinadas situações. Por meio do conhecimento de eventos, é possível saber que, em uma cena denotada pelo verbo prender, o participante policial provavelmente desempenharia a função de agente, e o participante ladrão provavelmente desempenharia a função de paciente. Algumas teorias propõem que os conhecimentos sobre eventos e estados estão representados, em nossa memória, sob o formato de esquemas (e.g., FERRETTI, MCRAE e HATHERALL, 2001). Tais esquemas estão organizados de modo que os participantes normalmente relacionados a um evento - como agentes típicos, pacientes, instrumentos e locais - tornem-se mais acessíveis sempre que uma representação esquemática for invocada.

Também chamados de conhecimentos enciclopédicos ou conhecimentos conceituais, os conhecimentos de eventos, muitas vezes, não são considerados parte do sistema linguístico, sendo tratados como representações conceituais gerais que estão armazenados em nossa memória de longo prazo. Em geral, as teorias separam as informações semânticas codificados na representação lexical - informações de dicionário - das informações conceituais provenientes dos conhecimentos de mundo - informações enciclopédicas - devido ao caráter variável e complexo do componente conceitual. Supostamente, os significados lexicalizados são considerados mais essenciais.

Nos últimos vinte anos, a discussão sobre a relevância dos conhecimentos de eventos para o processamento linguístico tornou-se bastante presente na literatura psicolinguística (e.g., FEDERMEIER e KUTAS, 1999; WARREN e MCCONNELL, 2007; METUSALEM et al., 2012; MILBURN, WARREN e DICKEY, 2016). Resultados de diferentes estudos indicam que conhecimentos sobre 
eventos do mundo real são ativados em estágios iniciais do processamento, inclusive possibilitando a antecipação de informações conceituais (OTTEN et al., 2005; MILBURN, WARREN e DICKEY, 2016) e gramaticais (DELONG et al., 2005).

Dentre os estudos que verificam a atuação de conhecimentos de eventos durante o processamento linguístico, o estudo de Bicknell et al. (2010) possui especial relevância para este trabalho. Utilizando sentenças que possuíam um contexto bastante simples, Bicknell et al. (2010) investigaram a ativação de conhecimentos de eventos durante processamento de argumentos verbais. No estudo, foram realizados dois experimentos: um primeiro experimento utilizando leitura autocadenciada e um segundo experimento utilizando potenciais evocados. Os pesquisadores observaram se o uso de determinados agentes estereotípicos restringia o evento descrito pelo verbo, facilitando o processamento de argumentos internos considerados previsíveis nesses eventos específicos. Os experimentos alternavam quatro condições como as expostas abaixo:

(1) O jornalista checou a ortografia do seu último relatório. (Argumento previsível)

(2) O mecânico checou os freios do carro. (Argumento previsível)

(3) O jornalista checou os freios do carro. (Argumento imprevisível)

(4) O mecânico checou a ortografia do seu último relatório². (Argumento imprevisível)

Os resultados do experimento de leitura autocadenciada indicaram um efeito de facilitação tardio, uma vez que os tempos de leitura eram

\footnotetext{
2 Versão original:

(1) The journalist checked the spelling of his latest report.

(2) The mechanic checked the brakes on the car.

(3) The journalist checked the brakes on the car.

(4) The mechanic checked the spelling of his latest report.
}

significativamente menores apenas nas palavras após argumento interno previsível. Contudo, os resultados do experimento de potenciais evocados ${ }^{3}$ mostraram uma perspectiva um pouco diferente, pois houve um efeito de facilitação no acesso a informações semânticas durante a leitura dos argumento internos previsíveis. Os argumentos internos previsíveis desencadeavam $\mathrm{N} 400 \mathrm{~s}^{4} \mathrm{com}$ amplitudes significativamente menores do que os argumentos internos imprevisíveis. Assim, embora em momentos distintos, ambos os experimentos reportaram efeito de facilitação relacionado à previsibilidade do argumento.

Uma das inovações do trabalho de Bicknell et al. (2005) em relação a trabalhos anteriores foi estudar o processamento em sentenças que careciam de um contexto prévio que pudesse fornecer mais informações pragmáticas que enriquecessem a representação discursiva. Essa manipulação permitiu investigar se a mera menção ao evento por meio de um arranjo de verbo com um argumento externo específico poderia influenciar o processamento linguístico, diferentemente dos estudos que encontraram efeitos semelhantes aos dos autores, mas cujo segmento crítico era apresentado somente após duas ou mais sentenças (VAN BERKUM et al., 2005). O estudo de Bicknell et al. (2010), portanto, indicou que o menor indício de conhecimento de mundo pode ser incorporado rapidamente pelo processador linguístico.

${ }^{3}$ No método de potenciais evocado, medidas dos potenciais elétricos gerados no cérebro em intervalos específicos de tempo são relacionadas diretamente às manipulações experimentais pré-estabelecidas. cérebro a processos cognitivos desempenhados especificamente nas tarefas experimentais (JAGER PARENTE, 2010)

${ }_{4} \mathrm{O}$ N400 é uma onda cerebral negativa cujo pico acontece em torno de $400 \mathrm{~ms}$ após a apresentação de um estímulo. Na literatura psicolinguística o N400 é conhecido como um índice de facilidade de acesso a informaç̃es de significado. Quanto maior a facilidade de acesso, menor a amplitude da onda. Em geral todas as palavras de conteúdo produzem o N400. Sabe- que sua amplitude é sensível anda. Em geral, todas as palavras de conteúdo produzzen o N que facilitem significados específicos (KUTAS et al., 2006) 
Em português brasileiro, um estudo atual investigou se "conhecimentos refinados sobre eventos no mundo real são ativados durante a leitura de sentenças com contextos reduzidos" (VIEIRA, 2015, p. 7). No entanto, os estímulos experimentais desse trabalho diferiram um pouco do estudo de Bicknell et al. (2010). Ao mesmo tempo em que reproduzia um contexto em que o argumento interno do verbo era previsível (cf. 5) ou imprevisível (cf. 6) pelo evento evocado pelo arranjo entre argumento externo e verbo, Vieira (2015) também criou contextos em que o mesmo verbo aparecia em contextos neutros, i.e., contextos em que o argumento externo, por ser um nome próprio, não evocava um evento específico (cf. 7 e 8). Os contextos neutros, então, se opunham a contextos preditivos, ou seja, contextos em que a probabilidade de ocorrência de uma palavra, e não outra, era maior.

(5) A garçonete anotou o pedido do casal sem muita atenção. (Argumento previsível para o contexto preditivo)

(6) A garçonete anotou o relato bíblico nas páginas do caderno. (Argumento imprevisível para o contexto preditivo)

(7) Mariana anotou o pedido do casal sem muita atenção. (Argumento imprevisível para o contexto neutro)

(8) Mariana anotou o relato bíblico nas páginas do caderno. (Argumento imprevisível para o contexto neutro)

O trabalho de Vieira (2015) previa que, se conhecimentos de eventos são ativados durante a leitura dessas sentenças, então a sentença (5) deveria ser menos custosa comparativamente a (6). Seria possível ainda que o processamento de (6) fosse mais custoso que as outras três condições, indicando dificuldade de integrar uma palavra não esperada ao contexto criado pelo evento específico.

Após submeter as condições acima a um experimento de rastreamento ocular, a autora reportou que os contextos criados pelos arranjos de argumentos externos e verbos não foram capazes de alterar os tempos de fixação na região do argumento interno. Tais dados não contrariam apenas os achados de Bicknell et al. (2010), cujo experimento foi desenhando para responder a questões semelhantes às de Vieira (2015), mas também os dados registrados na literatura que identificam, no processamento linguístico, influência oriunda de conhecimento de eventos (e.g., CHOW, 2013; KAMIDE et al., 2003).

Conforme argumentamos anteriormente, embora o impacto do conhecimento pragmático no processamento linguístico esteja bem documentado, ainda há de se fazer o trabalho de especificar como se dá essa influência. A divergência entre os dados de Vieira (2015) e de Bicknell et al. (2010) se apresenta como boa oportunidade para refletir sobre suas possíveis causas e, no processo, entender os mecanismos envolvidos na ativação de conhecimentos de eventos durante a compreensão da linguagem.

A hipótese com a qual trabalharemos aqui é a de que os resultados de Vieira (2015) decorrem da falta de controle da probabilidade de cloze dos argumentos internos previsíveis e imprevisíveis. A probabilidade de cloze de uma determinada palavra é a probabilidade com que ela aparece em determinado contexto. Se pedirmos para cem pessoas completarem a sentença "A garçonete anotou..." e noventa responderem algo como "o pedido", "o longo pedido", "o pedido do casal" etc., dizemos que a probabilidade de cloze da palavra "pedido", nesse contexto, é de 0,9 . Se 5 pessoas completarem com "o telefone", dizemos que "telefone", nesse contexto, tem uma probabilidade de cloze de 0,05.

Acredita-se que a probabilidade de cloze de uma palavra em determinado contexto é diretamente proporcional à facilidade de sua integração (KUTAS e HILLYARD, 1984). Sabendo disso, Vieira (2015) realizou uma série de experimentos de cloze para selecionar quais seriam os argumentos internos previsíveis de seus itens experimentais. No entanto, esses controles não 
garantiram, a nosso ver, contextos altamente preditivos, i.e., contextos em que havia uma alta probabilidade (mais de $50 \%$ de chance ${ }^{5}$ ) de que a continuação daquele evento apontasse para uma palavra específica.

Em primeiro lugar, destacamos que Vieira (2015) selecionou uma das três palavras mais frequentes obtidas em um teste de cloze, o que não garantiria, no entanto, que tal palavra tivesse uma alta probabilidade de ocorrência. A palavra "matéria", por exemplo, que a autora selecionou como argumento previsível na sentença "A repórter editou a matéria", por ter sido o item lexical com maior taxa de resposta para a frase "A repórter editou...", teve uma probabilidade de cloze em seu experimento de apenas 0,18 . Além disso, a fim de controlar o número de sílabas das palavras a serem apresentadas no experimento de rastreamento ocular, Vieira (2015) fez algumas substituições. Na sentença “o churrasqueiro fatiou...", por exemplo, a maior probabilidade de cloze foi da palavra "carne" $(0,64)$. Como decidiu apresentar argumentos internos de três silabas para manter consistência ao longo dos itens experimentais, a autora substituiu essa palavra por "picanha", que teve baixa probabilidade de cloze $(0,16)$ em seu experimento. Outros argumentos internos considerados previsíveis chegavam a ter probabilidade de cloze de apenas 0,06 ("ouvintes" em "A pianista comoveu os ouvintes").

Ainda que "carne" e "picanha" compartilhem um campo semântico, o que facilitaria a integração da última palavra a despeito de seu cloze baixo (FEDERMEIER e KUTAS, 1999), questionamos se essa manobra não geraria uma falha da previsão da palavra esperada, o que implicaria em maior custo de processamento e anulação de qualquer benefício supostamente causado pela ativação de conhecimento de eventos. Portanto, seria necessário que as

${ }^{5}$ Em uma consistente revisão teórica, Van Petten e Luka (2012, p.187) mostram que efeitos de
previsibilidade foram encontrados em estudos que utilizavam parâmetros de probabilidade alta de cloze que vão de 0,30 a 0,92. Para uma discussão mais aprofundada sobre cloze, cf. Staub et al. (2015). palavras previsíveis escolhidas fossem, de fato, aquelas que apresentassem a maior probabilidade de cloze em um experimento prévio, e, mais que isso, que apresentassem uma probabilidade de cloze alta.

Um detalhe menor, mas que também deve ser apontado, é o fato de a região posterior ao argumento interno das sentenças da autora serem diferentes para as palavras previsíveis e imprevisíveis. Principalmente em um experimento de rastreamento ocular, em que a visão parafoveal, por influenciar nos tempos de fixação (RAYNER, 1998), necessitaria que os contextos subsequentes da sentença fossem idênticos para garantir a qualidade dos resultados.

Nosso objetivo aqui, portanto, será o de replicar o experimento de Vieira (2015), porém com maior controle da probabilidade de cloze das palavras selecionadas como previsíveis e imprevisíveis. A hipótese principal é de que o conhecimento de evento é acessado durante o processamento de sentenças isoladas, mas esse efeito só será sentido caso esse evento possua uma força preditiva forte com relação à probabilidade de cloze da palavra prevista. Segundo essa hipótese, foi esse o motivo de Vieira (2015) não ter sido capaz de encontrar um efeito similar ao reportado por Bicknell et al. $(2010)^{6}$. Mais especificamente, e sabendo que a probabilidade de cloze é diretamente proporcional à facilidade de integração de um item lexical, acreditamos que a ativação de conhecimento de eventos levará a menor tempo de leitura do argumento interno em contextos preditivos, semelhantes à sentença em (5), comparativamente aos outros contextos. Para testar tal suposição, realizamos dois experimentos de cloze e um experimento de leitura autocadenciada, conforme descrevemos a seguir.

${ }^{6}$ Bicknell et al. (2010) realizaram um experimento de pergunta-resposta, um experimento de livre associação e um experimento de priming para construir seus itens experimentais. Por esse motivo, não reportam uma probabilidade de cloze para o argumento interno de seus itens, e é impossível saber qual seria sua força preditiva. 


\section{Experimentos ${ }^{7}$}

Para testar nossa hipótese, foi necessário construir sentenças em que o arranjo de um argumento externo com um verbo (doravante, $\mathrm{AE}+$ Verbo) gerasse um contexto preditivo que poderia levar à facilitação da leitura de um argumento interno específico. Mais que isso, seria necessário que o argumento externo, por meio de expressões definidas (e.g., "a garçonete"), evocasse um evento específico em conjunto com o verbo, uma vez que nosso objetivo foi testar se conhecimentos de evento desencadeados pelo arranjo AE+Verbo poderiam influenciar a leitura de trechos subsequentes das sentenças. Em um experimento de tempo de leitura, testamos a hipótese de que o aumento da probabilidade de cloze dos argumentos internos de sentenças semelhantes às de Vieira (2015) levaria à facilitação da leitura. Contudo, a fim de construir as sentenças experimentais, primeiramente foi necessário conduzir dois experimentos de cloze.

\subsection{Testes de Cloze}

Em nosso primeiro experimento de cloze, quisemos excluir verbos que subselecionassem com alta probabilidade um argumento interno específico. Esse seria o caso de verbos como "afiar", por exemplo, que, a despeito de qual seja o seu agente, tem uma alta probabilidade de selecionar "a faca" como argumento interno ${ }^{8}$. Esse controle foi feito para garantir que seria o arranjo AE+Verbo que levaria a uma facilitação de leitura do argumento interno específico, e não apenas uma subseleção de argumento interno desencadeada pelo verbo.

\footnotetext{
Os experimentos aqui descritos foram aprovados pelo Comitê de Ética da Universidade Federal do Rio Trande do Norte sob o protocolo de no 55184616.4.0000.5537.
}

8 Dados de Vieira (2015).

\subsubsection{Materiais e métodos: cloze 1}

Escolhemos 100 verbos transitivos que selecionam um objeto direto como argumento interno. Conforme se vê nos exemplos (9-11), foram criadas sentenças incompletas em que os agentes desses verbos eram nomes próprios, com o objetivo de criar contextos neutros que nos ajudassem a identificar - e excluir, posteriormente - verbos que, por si só, selecionavam um argumento interno específico.

(9) Artur atingiu...

(10) Felipe queimou...

(11) Joana anotou...

Por meio da plataforma googleforms, essas 100 sentenças incompletas foram organizadas em 10 blocos de 10 sentenças cada. Um total de 83 sujeitos (49 mulheres), falantes nativos de português brasileiro, com Ensino Superior completo ou cursando, entre 18 e 30 anos (média 24,8) participaram do experimento voluntariamente. Eles foram instruídos a completar as sentenças com a primeira continuação que lhes ocorresse, evitando humor.

\subsubsection{Análises: cloze 1}

Computou-se a frequência da palavra mais recorrente como núcleo do argumento interno em cada sentença para calcular sua probabilidade de cloze. Foram descartados dos experimentos subsequentes os verbos que (a) selecionavam com uma probabilidade de cloze maior que 0,4 um argumento interno específico; (b) selecionavam com uma probabilidade de cloze maior que 0,4 argumentos internos que compartilhavam um mesmo traço lexical. Ao todo, 9 verbos foram descartados. Além disso, 
descartou-se o verbo "conservou", que foi lido por boa parte dos participantes como "conversou".

\subsubsection{Materiais e métodos: cloze 2}

Em um segundo teste de cloze, construímos arranjos de AE+Verbo com os 90 verbos restantes do experimento anterior. Como agente, usamos expressões definidas que levassem os participantes a ativar seu conhecimento de eventos, o que, supostamente, restringiria a escolha do argumento interno.

(12) O goleiro agarrou...

(13) A garçonete anotou...

(14) A surfista executou...

As 90 sentenças foram organizadas em 10 blocos de 9 sentenças cada. Os procedimentos foram idênticos aos descritos para o experimento de cloze 1. Participaram voluntariamente 50 falantes nativos de português brasileiro (26 homens) com Ensino Superior completo ou cursando, entre 18 e 30 anos (média 20,36).

\subsubsection{Análise: cloze 2}

Foi feita a análise da frequência do núcleo do argumento interno mais frequente nas respostas dadas. 0 objetivo foi selecionar as sentenças mais preditivas, cujas respostas citadas tinham as probabilidades de ocorrência mais altas. Após análise, foram descartados 40 dos 90 arranjos testados pelo fato de o argumento interno da continuação mais frequente ter probabilidade de cloze inferior a 0,5 .

Os 50 arranjos restantes foram sentenças em que (a) o verbo, por si só, não selecionava um argumento interno específico, conforme determinado pelo experimento de cloze 1; (b) o verbo, em conjunto com uma expressão definida específica no papel de agente, gera uma alta probabilidade de cloze (maior que 0,5) para um determinado argumento interno, conforme determinado pelo experimento de cloze 2. Esses arranjos foram, então, utilizados para compor os itens de um experimento de tempo de leitura.

\subsection{Experimento de tempo de leitura}

A partir dos experimentos de cloze descritos, obteve-se um conjunto de 50 sentenças em que um contexto preditivo é determinado pelo evento denotado pelo arranjo AE+Verbo. A fim de testarmos se apenas o conhecimento de evento é capaz de facilitar a leitura de um argumento interno com alta probabilidade de ocorrência, foram feitos alguns ajustes que levaram ao descarte de 18 das 50 sentenças. Foram descartadas 12 sentenças em que o argumento interno mais frequente no Experimento de cloze 2 teve probabilidade superior a 0,05 no experimento de cloze 1 . Isso foi feito para garantir que a subseleção exclusiva do verbo não pudesse ser considerada causa de uma possível facilitação de leitura de argumentos internos. Para manter um controle de frequência, também foram excluídas 6 sentenças em que o argumento interno esperado tinha frequência inferior a 10 ou superior a 300 por milhão ${ }^{9}$. O resultado foi um conjunto de 32 sentenças de contexto preditivo, com argumentos internos de duas ou três sílabas, que foi usado em um experimento de leitura autocadenciada para determinar se apenas a informação de evento é suficiente para facilitar a leitura de um argumento interno.

Para a realização desse teste foram controladas duas variáveis independentes: o tipo de argumento externo (estereótipo $\times$ nome próprio) e

9 Para fazer os cálculos de frequência, utilizamos o corpus "ptTenTen [2011, Freeling v3]" da ferramenta sketch engine. 
a previsibilidade do argumento interno verbal (previsível × imprevisível). As palavras previsíveis eram aquelas com alta probabilidade de cloze de acordo com o teste de cloze 2. As palavras imprevisíveis, assim como as previsíveis, foram controladas por tamanho, por frequência e possuíam probabilidade de cloze menor que 0,05 em qualquer um dos testes realizados (Tab. 2). Seguindo este modelo, obtivemos quatro condições conforme listado na Tabela 1.

Tabela 1 - Exemplos de condições para o experimento de tempo de leitura

\begin{tabular}{ll}
\hline Condição & Sentença \\
AE estereotípico $\times$ AI previsível & A garçonete / anotou / o pedido / importante/ no seu caderno. \\
AE estereotípico $\times$ AI imprevisível & A garçonete / anotou / o relato / importante/ no seu caderno. \\
AE nome próprio × AI previsível & Joana / anotou / o pedido / importante/ no seu caderno. \\
AE nome próprio × AI imprevisível & Joana / anotou / o relato / importante/ no seu caderno.
\end{tabular}

Vale mencionar que, embora usemos o termo "palavra previsível" para nomear as variáveis controladas, a previsibilidade, determinada por alta probabilidade de cloze, se dava apenas na condição $A E$ estereotípico $\times A I$ imprevisível, conforme descrito na Tabela 2.

Tabela 2 - Média da probabilidade de cloze por condição dos argumentos internos usados no experimento

\begin{tabular}{lc}
\hline Condição & Média da probabilidade de cloze do AI \\
\hline AE estereotípico × AI previsível & 0,63 \\
AE estereotípico × AI imprevisível & 0,001 \\
AE nome próprio × AI previsível & 0,02 \\
AE nome próprio × AI imprevisível & 0,009 \\
\hline
\end{tabular}

Para a criação dos 32 materiais experimentais, controlamos o tamanho do argumento interno, que possuía duas ou três silabas, e seu gênero gramatical. Para os 16 itens em que a palavra previsível tinha três sílabas, a palavra imprevisível que a substituía nas outras condições também tinha três sílabas e possuía o mesmo gênero gramatical. Para os outros 16 itens, que tinham argumentos internos de duas sílabas nas condições de palavra previsível, as palavras imprevisíveis que as substituíam também tinham duas sílabas e o mesmo gênero gramatical. Optamos por variar o número de sílabas entre duas e três para manter as palavras que foram efetivamente informadas pelos sujeitos nos testes de cloze. Assim, evitamos utilizar palavras de campos semânticos relacionados, porém de baixa probabilidade de cloze, como fez Vieira (2015). Por fim, para controlar efeitos de spill-over, os núcleos do argumento interno eram seguidos sempre por um adjunto adnominal de quatro sílabas que era o mesmo nas quatro condições.

A partir dos critérios expostos, criamos arranjos formados por um argumento externo estereotípico associado a um verbo. Tais arranjos gerariam um contexto preditivo o suficiente para a ocorrência de facilitação de leitura de um argumento interno previsível.

Foram criados 32 conjuntos de itens experimentais que seguem as condições apresentadas anteriormente. Esses itens foram separados em quatro listas distintas de modo que cada lista tinha apenas uma condição para cada item. Foram acrescentadas 32 sentenças distratoras, resultando em 64 frases por lista.

\subsubsection{Métodos}

Participaram voluntariamente 24 falantes nativos de português brasileiro (13 mulheres) com idade entre 18 e 28 anos, alunos da Universidade Federal do Rio Grande do Norte. Utilizando o software Psychopy, os itens de cada lista foram apresentados de forma não-cumulativa por meio de uma tarefa 
de leitura autocadenciada, i.e., cada trecho das sentenças foi apresentado no centro da tela de um laptop com tela de 13 polegadas, e os participantes controlaram o ritmo de apresentação pressionando a barra de espaço do teclado. Os itens experimentais foram segmentados conforme demonstrado na Tab. 1. Antes do início de cada item experimental ou distrator, havia um sinal de positivo no meio da tela para que os voluntários concentrassem seu olhar na região onde o texto apareceria. Após cada item, o voluntário deveria responder "sim" ou "não" para uma pergunta feita sobre a sentença. Não havia tempo limite para o registro da resposta.

\subsubsection{Análise e Resultados}

Os 24 participantes acertaram mais de $80 \%$ do total das perguntas das 64 sentenças e mais de $80 \%$ do total de perguntas dos 32 itens experimentais. Foram excluídos os tempos de leitura das sentenças experimentais em que o participante errou a resposta da pergunta de interpretação $(3,38 \%$ do total de observações).

Nossa variável de interesse foi o tempo de leitura do argumento interno e de seu adjunto adnominal nas quatro condições. Devido às discussões recentes sobre o uso apropriado de análises de variância para dados de tempo de reação (BAAYEN et al., 2008), os resultados deste experimento foram analisados através de um método de modelagem estatística conhecido como modelos mistos. Baayen et al. (2008) apresentam uma das primeiras aplicações desta técnica em dados de tempo de reação, abrindo assim um leque de novas possibilidades para a análise destes experimentos.

Modelos mistos recebem este nome por serem capazes de lidar simultaneamente com o efeito geral das condições do experimento e o efeito particular de cada sujeito nessas condições. Esses modelos são particularmente úteis quando os sujeitos são submetidos a medições repetidas. Se cada sujeito tiver o seu tempo de reação medido mais de uma vez, em situações diferentes, não podemos assumir que estes resultados são independentes entre si. Desse modo, as técnicas tradicionais, como ANOVA, não são as mais indicadas para a análise desse tipo de experimento. A vantagem dos modelos mistos sobre os métodos tradicionais é modelar o efeito que cada sujeito tem nas condições. Assim, estes modelos permitem a modelagem da estrutura de cada um dos sujeitos nos resultados do experimento.

Devido à não-normalidade dos dados, procedemos com a sua transformação através do logaritmo natural. Ajustamos os modelos com o auxílio do pacote lme4 do software R (BATES et al., 2015). Os modelos mistos apresentam dois tipos de efeitos, chamados respectivamente de efeitos fixos e efeitos aleatórios. Os efeitos fixos são aqueles cujos níveis são controlados pelo pesquisador. Neste trabalho, os efeitos fixos são argumento externo, com os níveis estereotípico e nome próprio, e argumento interno, com os níveis previsível e imprevisível. Os efeitos aleatórios são aqueles cujos níveis não podem ser controlados pelo pesquisador. Em geral, são sorteados a partir de uma população. Os efeitos fixos em experimentos de psicolinguística normalmente são sujeitos e itens experimentais (BAAYEN et al., 2008). Neste trabalho, além destes dois efeitos, consideramos a influência dos itens experimentais aninhados dentro das listas que foram apresentadas aos sujeitos.

Modelos mistos não possuem maneiras diretas de determinar o p-valor dos efeitos fixos estudados. McCullagh e Nelder (1989) sugerem que se inicie o ajuste dos dados com o modelo mais complexo possível e, a partir dele, os testes sejam realizados com modelos aninhados, através de um teste de razão de verossimilhanças. Dizemos que o modelo A está aninhado no modelo $B$ se duas condições são satisfeitas: i) todas variáveis do modelo A estão no modelo B; e ii) o modelo B possui mais variáveis do que o modelo A. 
A partir desses parâmetros, definimos o modelo completo como aquele que considera como efeitos fixos os argumentos interno e externo, simultaneamente. Os efeitos aleatórios considerados foram sujeito, item e item aninhado na lista.

Com isso, o modelo completo é definido como

Imer(argint $\sim$ condicaoai ${ }^{*}$ condicaoae + (1|itemInLista $)+(1 \mid$ lista $)+(1 \mid$ participant $)$, REML=FALSE, data=dados)

Para determinar a significância dos efeitos fixos dos argumentos interno e externo e da interação entre eles, realizamos testes de razão de verossimilhança. $\mathrm{O}$ modelo completo foi sendo simplificado, o que significa que cada variável foi sendo retirada em sequência, até chegarmos ao modelo mais simples possível, em que o tempo de resposta foi explicado apenas pela média comum entre os grupos. A Tabela 3 apresenta os resultados desta análise.

Tabela 3 - Resultados do teste de razão de verossimilhanças entre os diversos modelos considerados - argumento interno

\begin{tabular}{lccccc}
\hline Modelo & gl & AIC & BIC & log-Verossimilhança & $\boldsymbol{p}$-valor \\
condicaoai*condicaoae & 8 & 452,4 & 489,3 & $-218,2$ & 0,5308 \\
condicaoai+condicaoae & 7 & 450,8 & 483,1 & $-218,4$ & 0,2700 \\
condicaoae & 6 & 450,0 & 477,7 & $-219,0$ & 0,6541 \\
condicaoai & 6 & 449,0 & 476,7 & $-218,5$ & 0,2705 \\
\hline
\end{tabular}

Como podemos ver, à medida que o modelo foi sendo simplificado, os testes de razão de verossimilhanças permaneceram não-significantes. Logo, podemos concluir que tanto o modelo completo, com todas as variáveis controladas no estudo, quanto o modelo simples, que considera uma média comum para todas as condições, explicam os dados de maneira equivalente.
De acordo com Bates et al. (2015), quando dois ou mais modelos concorrentes explicam os dados com a mesma qualidade, escolhemos o modelo mais simples como o que melhor se ajusta aos dados. Assim, optamos pelo modelo simples, que considera a média como suficiente para explicar os resultados obtidos, para modelar os dados do experimento. Portanto, não há influência significativa dos efeitos fixos no experimento.

A falta de efeito das variáveis controladas também foi reportada para análise dos tempos de leitura da região pós-crítica, em que havia sempre um adjunto adnominal (Tab. 4).

Tabela 4 - Resultados do teste de razão de verossimilhanças entre os diversos modelos considerados - região pós-crítica

\begin{tabular}{lccccc}
\hline Modelo & gl & AIC & BIC & log-Verossimilhança & $p$-valor \\
condicaoai*condicaoae & 8 & 504,0 & 540,9 & $-244,0$ & 0,7727 \\
condicaoai+condicaoae & 7 & 502,1 & 534,4 & $-244,1$ & 0,9215 \\
condicaoae & 6 & 500,1 & 527,8 & $-244,0$ & 0,2703 \\
condicaoai & 6 & 501,3 & 529,0 & $-244,7$ & 0,9216 \\
\hline
\end{tabular}

\section{Discussão}

Em nosso experimento, prevíamos que um tempo de leitura menor do argumento interno da condição "AE estereotípico + AI previsível" frente às outras condições seria indicativo da atuação de conhecimento de eventos no processamento linguístico. Nesse caso, poderíamos considerar que tal arranjo geraria um contexto preditivo de forma a permitir a facilitação de leitura do argumento interno previsível. Como fizemos um controle de cloze mais rigoroso que Vieira (2015), tal resultado ainda indicaria que o efeito seria sentido apenas em situações com probabilidades de cloze realmente altas. Em nossas análises, contudo, não identificamos nenhuma tendência nesse 
sentido. O tempo de leitura do argumento interno do verbo, bem como do adjunto adnominal que o seguia, foi similar nas quatro condições.

Primeiramente, reiteramos que seria inadequado, com base nos resultados aqui expostos, defender a posição de que o conhecimento pragmático não impacta ou impacta pouco/tardiamente o processamento linguístico. Como já argumentamos, há uma série de evidências acumuladas nas últimas décadas que torna tal posição insustentável (FEDERMEIER e KUTAS, 1999; DELONG et al., 2005; VAN BERKUM et al., 2005, inter alia), mesmo que ainda haja questões abertas sobre como esse tipo de conhecimento atua durante a compreensão da linguagem (KUPERBERG, 2016).

O objetivo inicial deste trabalho, porém, não foi questionar se conhecimento pragmático impacta o processamento linguístico, mas sim averiguar quão preditivo deveria ser um contexto para que esse efeito fosse sentido. Considerando os resultados aqui reportados, bem como os de Vieira (2015), há possibilidade de questionar se o conhecimento de evento realmente influenciaria o processamento de forma significativa. Contudo, os resultados da literatura não sustentam tal questionamento. Bicknell et al. (2010), por exemplo, apresentam indícios claros de influência de conhecimento de eventos no processamento através de um experimento de eletroencefalografia já descrito. Também fazendo uso de eletroencefalografia, Chow (2013) identificou que a inversão de papeis temáticos típicos (e.g., "o ladrão prendeu o policial" ao invés de "o policial prendeu o ladrão") gera um custo cognitivo, embora não fique clara qual seria a natureza de tal custo ${ }^{10}$. Portanto, parece razoável admitir que técnicas de eletroencefalografia conseguem capturar efeitos provocados por conhecimentos de eventos em estágios iniciais do processamento linguístico, o que invalidaria o argumento

${ }^{10}$ Pelo que se sabe sobre potenciais evocados, esperaria-se a ocorrência de um N400 mais pronunciado no caso de inversão de papeis temáticos. No entanto, os autores registraram um efeito de P600. de que nossos resultados mostrariam que conhecimentos de eventos não influenciam tal processo. Há, contudo, três explicações alternativas para os dados aqui obtidos que merecem atenção e futuras pesquisas para que se decida por uma delas.

\subsection{A natureza das diferenças reportadas por Bicknell et al. (2010)}

A fim de explicarmos o porquê de não termos encontrado achado semelhante ao de Bicknell et al. (2010), convém considerarmos que condições, exatamente, os autores compararam. Como dito anteriormente, os autores compararam o custo de processamento de palavras que, com base no conhecimento de eventos, seriam esperadas ou inesperadas. No entanto, não se comparou um contexto altamente preditivo com um contexto neutro, como fizemos. Retomando abaixo seus itens experimentais, percebemos que a comparação se deu entre contextos que sempre eram preditivos de uma palavra específica, mas cuja predição ora era satisfeita (cf. 1-2), ora era violada (cf. 3-4).

(1) O jornalista verificou a ortografia do seu último relatório.

(2) O mecânico verificou os freios do carro.

(3) O jornalista verificou os freios do carro.

(4) O mecânico verificou a ortografia do seu último relatório.

O experimento de Bicknell et al. (2010), portanto, apresenta um efeito que não significa, necessariamente, facilitação de processamento do argumento interno previsível. Uma explicação alternativa seria de que a diferença registrada se deve à dificuldade de processamento de um argumento quando este viola as expectativas de um contexto preditivo. Portanto, uma possível explicação para os dados dos dois estudos seria de que não há facilitação gerada por um contexto preditivo (nosso experimento), mas há dificuldade 
oriunda da quebra das expectativas geradas por esse contexto preditivo (no caso de Bicknell et al., 2010).

Embora essa hipótese seja possível, cabe aqui uma ressalva: se o efeito encontrado pelos autores no tempo de leitura do argumento interno do verbo fosse a diferença entre uma expectativa satisfeita e uma expectativa frustrada, deveríamos ter observado a mesma diferença entre as condições "AE estereotípico + AI previsível" e "AE estereotípico + AI imprevisível", que repetimos abaixo:

(5) A garçonete anotou o pedido importante no seu caderno.

(6) A garçonete anotou o relato importante no seu caderno.

Ainda que haja semelhança entre as duas condições acima e as condições experimentais de Bicknell et al. (2010), deve-se ter cautela em presumir que um (suposto) efeito da diferença entre expectativa satisfeita e expectativa frustrada do experimento dos autores seria transposta para nosso experimento, uma vez que ambos os testes controlavam variáveis diferentes e foram delineados de modo distinto. No experimento de Bicknell et al. (2010), por exemplo, a taxa de contextos preditivos com expectativas confirmadas era o dobro da utilizada em nosso experimento, o que pode ter encorajado os participantes a fazerem mais uso de pistas pragmáticas (LAU et al., 2013). Apenas uma replicação exata do trabalho dos autores poderia esclarecer melhor esses pontos, e, portanto, a possibilidade de que a diferença entre os experimentos se deve à natureza do efeito reportado por Bicknell et al. (2010) não pode ser descartada de imediato.

\subsection{Estratégias de processamento}

Uma segunda explicação para nossos dados relaciona-se com as diferentes estratégias que os leitores podem assumir para atingir a com- preensão de um texto e, consequentemente, lidar com uma tarefa experimental.

Como nosso objetivo foi avaliar o impacto do conhecimento de evento no processamento linguístico, construímos sentenças isoladas, de modo que a única informação inferível através de conhecimentos pragmáticos fosse aquela relacionada ao evento denotado. Bicknell et al. (2010) fizeram o mesmo, mas com uma diferença: suas sentenças faziam parte de textos mais longos (cf. 15). Embora a sentença experimental fosse sempre a primeira de um pequeno parágrafo, de modo a garantir que os participantes não tivessem qualquer informação além daquelas relacionados ao evento no momento de sua leitura, essa sentença era sempre seguida por uma outra, com a qual compunha uma história.

(15) O jornalista checou a ortografia de seu último relatório enviado ao editor Seu editor era chato com ortografia e fazia com que todos no jornal ficassem obcecados com isso também.

A nosso ver, o uso de histórias completas ou sentenças isoladas pode levar o participante a adotar estratégias distintas de processamento. Essa hipótese assenta-se em evidências de que o processamento linguístico é adaptável a situações específicas e, principalmente, responde de forma diferente a conjuntos de estímulos experimentais que podem ser idênticos, mas que estão inseridos em tarefas ou contextos distintos (e.g. SWETS et al., 2008; KURUMADA et al., 2012).

Nessa perspectiva, não se considera que os leitores/ouvintes/falantes utilizem apenas os padrões estatísticos derivados de sua experiência prévia, como preveem os modelos baseados em restrições já clássicos (MACDONALD et al., 1994; SEIDENBERG e MACDONALD, 1999), mas argumenta-se que o interactante também absorve estatísticas do novo ambiente (experimental), sejam elas padrões derivados a partir de estruturas sintáticas (FINE et al., 
2013) ou de informações sobre o falante e suas atitudes (YILDIRIM et al., 2015; BUZ et al., 2016). Como consequência, o tipo de tarefa demandada em um experimento pode fazer com que participantes de experimentos psicolinguísticos construam representações discursivas com diferentes graus de profundidade, ainda que recebam os mesmos itens experimentais (XIANG e KUPERBERG, 2015). Essa variabilidade seria uma vantagem do processador, uma vez que os diferentes objetivos comunicativos do dia-a-dia levariam os interactantes a adotarem estratégias distintas para o processamento do sinal linguístico (cf. KUPERBERG e JAEGER, 2015 para uma discussão).

Se considerarmos essa literatura, é possível supor que as frases isoladas e breves, apresentadas em apenas 5 segmentos, não demandassem dos sujeitos a construção de uma representação discursiva robusta o bastante para que o conhecimento de evento influenciasse sensivelmente o processamento linguístico. Por outro lado, o uso de histórias como itens experimentais poderia forçar a construção de um modelo situacional (ZWAAN e RADVANSKY, 1998) e a retenção das informações de diversas ordens (inclusive pragmáticas), que poderiam ser usadas posteriormente para relacionar as diferentes sentenças do texto e inferir seu sentido completo.

Ressaltamos que essa interpretação para nossos dados não pressupõe que informações de ordem pragmática ajam sobre o processamento linguístico somente após a construção de uma representação discursiva rica em detalhes a partir dos quais se pode inferir esquemas, eventos e seus participantes. A premissa assumida é de que o processador, mesmo em contextos limitados em informação pragmática, pode fazer uso substancial dessas informações se as identificar como pistas relevantes para resolver a tarefa em mãos.

\subsection{Falta de acurácia da técnica de leitura autocadenciada}

Por fim, uma análise mais atenta dos resultados do experimento de leitura autocadenciada conduzido por Bicknell et al. (2010) levanta uma última possibilidade de interpretação para nossos dados: de que a técnica que usamos não é sensível o bastante para capturar os efeitos causados por conhecimentos de evento.

O mesmo efeito encontrado no experimento de eletroencefalografia dos autores - maior facilidade de processamento para o processamento de frases como (1) e (2) comparativamente a (3) e (4) - foi reportado para um experimento de leitura autocadenciada. Entretanto, o efeito não foi registrado pelos tempos de leitura da palavra crítica, mas sim pelos tempos registrados para a leitura da palavra subsequente. Embora o efeito de espalhamento (ou spill-over effect) seja comum no uso dessa técnica, seus dados devem ser analisados com cuidado, principalmente quando são fruto de análise post-hoc, i.e., principalmente quando não se prevê tal efeito no experimento e a região não é objeto de controle de eventuais variáveis de influência no processamento. No caso do experimento de Bicknell et al. (2010), a palavra subsequente não foi controlada com relação a seu tamanho ou a sua função gramatical na sentença.

A análise estatística seguiu uma normalização dos tempos de leitura pelo número de caracteres, o que serviria para controlar efeitos de tamanho de palavra. Contudo as palavras utilizadas no segmento subsequente ao crítico cumpriam funções variadas na sentença, sendo por vezes preposições (e.g., of, for, with), verbos (e.g., looking), advérbios (e.g., before, whenever, quickly) ou pronomes relativos (e.g., that, who). Essa diversidade faz com que o processamento da palavra implique processos tão distintos quanto a elaboração de uma nova sentença subordinada ou a elaboração do evento em foco, e essa falta de controle demanda cautela na interpretação das possíveis causas dos efeitos capturados. Portanto, embora seja possível que o efeito registrado se dê pelas variáveis manipuladas, essa não é a única explicação viável. É possível também que as diferenças de tempo de leitura no segmento após a palavra crítica 
sejam efeito espúrio resultado da falta de controle experimental desse segmento.

\section{Conclusão}

Realizamos um experimento para averiguar se contextos que se tornam preditivos por força de conhecimentos de eventos influenciariam o processamento linguístico de um argumento interno com alta probabilidade de cloze. Os resultados obtidos não mostram qualquer efeito perceptível nesse sentido, mas sua comparação com estudos prévios levanta três hipóteses para explicar os dados empíricos disponíveis na literatura. Em primeiro lugar, negamos que nossos resultados indiquem a inexistência de influência de informações pragmáticas ou de eventos no processamento linguístico, um fenômeno largamente documentado em estudos experimentais. Assim, nossa primeira hipótese seria de que as diferenças entre as variáveis controladas do nosso experimento e de experimentos prévios poderia explicar a disparidade de resultados. Por essa perspectiva, experimentos prévios investigaram um efeito - a relação entre confirmação e frustração de expectativas - que nosso experimento não foi delineado satisfatoriamente para capturar.

Uma segunda hipótese, mais provável, seria a de que o modo como os estímulos experimentais foram construídos levou à adoção de estratégias distintas de processamento pelos participantes da pesquisa. Estudos anteriores criaram contextos que incentivavam o uso de pistas pragmáticas para o cumprimento da tarefa, enquanto o nosso, ao apresentar sentenças isoladas, pode ter levado a um processamento superficial dessas pistas. Essa hipótese vai ao encontro de modelos de processamento que assumem que os objetivos comunicativos são capazes de influenciar o modo como o input linguístico é processado (KUPERBERG e JAEGER, 2015).
Por fim, uma terceira hipótese seria de que a técnica de leitura autocadenciada não é sensível o bastante para capturar os efeitos mais comumente encontrados em estudos de eletroencefalografia. Tal conclusão se deve não apenas aos nossos resultados, mas a uma análise mais atenta dos resultados do experimento de leitura autocadenciada que motivou o presente trabalho.

Dentre as três hipóteses destacas, a segunda nos parece mais provável para explicar os resultados encontrados aqui e sua disparidade em relação aos estudos prévios. Contudo, apenas a testagem dessas hipóteses por meio de futuras pesquisas experimentais é capaz de validá-las ou descartá-las. Assim, consideramos que o estudo do fenômeno em questão ainda apresenta inúmeros aspectos que não estão satisfatoriamente explicados, e sua investigação é um passo importante para compreendermos, futuramente, como as informações pragmáticas são incorporadas ao processamento linguístico de forma bem-sucedida.

\section{Referências}

BAAYEN, R. Harald; DAVIDSON, D.; BATES, Douglas, M. Mixed-effects modeling with crossed random effects for subjects and items. Journal of Memory and Language, v. 59, p. 390-412, mar. 2008.

BÁSKÁNOVA, Jana; VAN BERKUM, Jos J. A.; WEBER, Kirsten; HAGOORT, Peter. A job interview in the MRI scanner: How does indirectness affect addressees and overhearers? Neuropsychologia, v. 76, p. 79-91, abr. 2015.

BATES, Douglas; MÄCHLER, Martin; BOLKER, Benjamin B.; WALKER, Steven C. Fitting Linear Mixed-Effects Models Using lme4. Journal of Statistical Software, v. 67, n. 1, p. 1-48, 2015.

BICKNELL, K.; ELMAN, J.; HARE, M.; MCRAE, K.; KUTAS, M. Effects of event knowledge in processing verbal arguments. Journal of Memory and Language, v. 63, p. 489-505, 2010. BUZ, Esteban; TANENHAUS, Michael; JAEGER, T. Florian. Dynamically adapted contextspecific hyper-articulation: Feedback from interlocutors affects speakers' subsequent pronunciations. Journal of Memory and Language, fev. 2016. 
CHOW, Wing Yee. The Temporal Dimension of Linguistic Prediction. PhD Dissertation, University of Maryland, 2013.

DELONG, K.; URBACH, T.; KUTAS, M. Probabilistic word pre-activation during language comprehension inferred from electrical brain activity. Nature Neuroscience, v. 8, p. 1117-1121, 2005

FEDERMEIER K.; KUTAS M. A rose by any other name: long-term memory structure and sentence processing. Journal of Memory and Language, v. 41, p. 469-495, 1999.

FERRETTI, Todd R.; MCRAE, Ken; HATHERELL, Andrea. Integrating Verbs, Situation Schemas, and Thematic Role Concepts. Journal of Memory and Language, v. 44, p. 516-547, maio 2001 .

FINE, Alex B.; JAEGER, T. Florian; FARMER, Thomas A.; QIAN, Ting. Rapid expectation adaptation during syntactic comprehension. PLoS ONE, out. 2013.

GODOY, Mahayana; VIEIRA, Cláudia B.; CUNHA LIMA, Maria Luiza. Antecipação e processamento linguístico: uma revisão das principais evidências a favor da previsão. Signo, v. 41, n. 71, p. 63-74, maio-ago. 2016

HAGOORT, Peter; HALD, Lea A.; BASTIAANSEN, Marcel C. M.; PETERSSON, Karl. Integration of word meaning and world knowledge in language comprehension. Science, v. 304 , p. $438-441$, abr. 2004

JAGER, A.; PARENTE, M.A. Cognição e eletrofisiologia: uma revisão crítica das perspectivas nacionais. Psico-USF, v. 15, p. 171-180, 2010.

KAMIDE, Yuki; ALTMANN, Gerry TM; HAYWOOD, Sarah L. The time-course of prediction in incremental sentence processing: Evidence from anticipatory eye movements. Journal of Memory and Language, v. 49, n. 1, p. 133-156, jul. 2003.

KUPERBERG, Gina R. Separate streams or probabilistic inference? What the N400 can tell us about the comprehension of events. Language, Cognition and Neuroscience, p. 1-15, jan. 2016.

KUPERBERG, Gina. R.; JAEGER, T. Florian. What do we mean by prediction in language comprehension? Language, Cognition and Neuroscience, v. 31, n. 1, p. 32-50, nov. 2015.

KURUMADA, Chigusa; BROWN, Meredith; TANENHAUS, Michael K. Pragmatic interpretation of contrastive prosody: It looks like speech adaptation. The proceedings of the 35th annual meeting of the Cognitive Science Society, Sapporo, Japan, ago. 2012.

KUTAS, Marta; HILLYARD, Steven A. Brain potentials during reading reflect word expectancy and semantic association. Nature, v. 307, n. 5947, p. 1161-1163, jan. 1984
LAU, Ellen; HOLCOMB, Phillip J.; KUPERBERG, Gina R. Dissociating N400 effects of prediction from association in single word contexts. Journal of Cognitive Neuroscience, v. 25, n.3, p. 484-502, 2013.

MCCULLAGH, Peter e NELDER, John Ashworth. Generalized Linear Models, 2. ed. Taylor \& Francis. 1989.

MACDONALD Maryellen C.; PEARLMUTTR, Neal J.; SEIDENBERG, Mark S. The lexical nature of syntactic ambiguity resolution. Psychological Review, v. 101, p. 676-703, 1994. METUSALEM, Ross; KUTAS, Marta; URBACH, Thomas; HARE, Mary; MCRAE, Ken; ELMAN, Jeffrey. Generalized event knowledge activation during online sentence comprehension, Journal of Memory and Language, jan. 2012.

MILBURN, Evelyn; WARREN, Tessa; DICKEY, Michael Walsh. World knowledge affects prediction as quickly as selectional restrictions: evidence from the visual world paradigm. Language, Cognition and Neuroscience, v. 31, n. 4, p. 536-548, 2016.

NIEUWLAND, Mante; Ditman, Tali; KUPERBERG, Gina R. On the incrementality of pragmatic processing: An ERP investigation of informativeness and pragmatic abilities. Journal of Memory and Language, v. 63, n. 3, p. 324-346, jul. 2010.

NIEUWLAND, Mante; VAN BERKUM, Jos. A. When peanuts fall in love: N400 evidence for the power of discourse. Journal of Cognitive Neuroscience, v. 18, p. 1098-1111, 2006.

OTTEN, M.; VAN BERKUM, J. A. Discourse-based word anticipation during language processing: Prediction of priming? Discourse Processes, v. 45, p. 464-496, 2008.

SEIDENBERG, Mark S.; MACDONALD, Maryellen C. A probabilistic constraints approach to language acquisition and processing. Cognitive science, v. 23, p. 569-588, 1999.

STAUB, Adrian; GRANT, Margaret; ASTHEIMER, Lori; COHEN, Andrew. The influence of cloze probability and item constraint on cloze task response time. Journal of Memory and Language, v. 82, p. 1-17, 2015.

SWETS, Benjamin; DESMET, Timothy; CLIFTON, Charles, Jr.; FERREIRA, Fernanda. Underspecification of syntactic ambiguities: Evidence from self-paced reading. Memory \& Cognition, v. 36, p. 201-216, jan. 2008.

TANENHAUS, Michael K. Eye movements as a window into real-time spoken language comprehension in natural contexts. Journal of Psycholinguistic Research, 24, 1995.

VAN BERKUM, Jos J. A. The neuropragmatics of 'simple' utterance comprehension: An ERP review. In: SAUERLAND, U.; YATSUSHIRO, K. (Ed.). Semantics and pragmatics: from experiment to theory. Basingstoke: Palgrave Macmillan, 2009. p. 276-316. 
VAN BERKUM, Jos J. A; BROWN, Colin M.; ZWITSERLOOD, Pienie; KOOIJMAN, Valesca; HAGOORT, Peter. Anticipating upcoming words in discourse: evidence from ERPs and reading times. Journal of Experimental Psychology: Learning, Memory, and Cognition, v. 31 , n. 3, p. 443, maio 2005 .

VAN PETTEN, Cyma; LUKA, Barbara J. Prediction during language comprehension: Benefits, costs, and ERP components. International Journal of Psychophysiology, v. 83, n. 2, p. 176-190, 2012.

VIEIRA, Cláudia. B. A atuação de conhecimentos de eventos na compreensão da leitura. 2015. 104 f. Dissertação (Mestrado em Linguística) - Curso de Pós-Graduação em Estudos Linguísticos, Faculdade de Letras, Universidade Federal de Minas Gerais, Belo Horizonte, 2015

XIANG, Ming; KUPERBERG, Gina R. Reversing expectations during discourse comprehension. Language, Cognition, and Neuroscience. v. 30, n. 6, p. 648-672, 2015.

WARREN, Tessa; MCCONNELL, Kerry. Investigating effects of selectional restriction violations and plausibility violation severity on eyemovements in reading. Psychonomic Bulletin \& Review, v. 14, p. 770-775, 2007.

WICHA, Nicole Y.; MORENO, Eva M.; KUTAS, Marta. Anticipating words and their gender: an event related brain potential study of semantic integration, gender expectancy, and gender agreement in Spanish sentence reading. Journal of Cognitive Neuroscience, v. 16, n. 7, p. $1272-1288$, set. 2004.

YILDIRIM, Ilker; DEGEN, Judith; TANENHAUS, Michael K.; JAEGER, T. Florian. Talkerspecificity and adaptation in quantifier interpretation. Journal of Memory and Language, v. 87 , p. 128-143, abr. 2016

ZWAAN, Rolf A.; RADVANSKY, Gabriel A. Situation models in language comprehension and memory. Psychological Bulletin, v. 123, n. 2, p. 162-185, 1998.

Recebido em 25/01/2017

Aceito em $07 / 07 / 2017$ 